\title{
COPD Care in the 21st Century: A Public Health Priority
}

\author{
Rachel N Criner MD and MeiLan K Han MD MS
}

\author{
Introduction \\ Epidemiology \\ Economic Burden \\ Impact on the United States Economy \\ Impact on Patients and Their Caregivers \\ Disparities \\ Age \\ Race \\ Gender \\ Socioeconomic \\ Out-Patient Management \\ Role of the Primary Care Physician \\ Preventive Health: Tobacco Cessation \\ Pulmonary Rehabilitation \\ Curbing Readmission Rates \\ Electronic Order Sets \\ Discharge Bundles \\ Hospital at Home \\ Telemedicine \\ Future Directions: COPD National Action Plan \\ Summary
}

COPD is an underdiagnosed, undertreated, and yet largely preventable disease. COPD affects millions of Americans on a daily basis, accounts for tens of thousands of deaths per year, and costs billions to the United States health-care system annually. Further, it impacts the quality of life for patients living with the disease. COPD care is fragmented in the United States, with a high level of responsibility placed on patients and their primary care physicians. Pulmonary specialists care for a minority of patients with COPD in the United States. Unfortunately, tobacco dependence, which is the leading cause of COPD, remains prevalent. Further, women and those with low socioeconomic status continue to share a relatively greater burden of disease. Exacerbations are experienced frequently by patients and contribute to high rates of emergency department visits and in-patient admissions and readmissions as well as high medical costs to the United States economy. Numerous strategies have been proposed to combat these high rates, including the use of discharge bundles, hospital at-home programs, telemedicine, and tele-rehabilitation, but no single best strategy has emerged. The COPD National Action Plan was introduced in 2017 as part of a multi-stakeholder endeavor to encourage collaboration among various patients, caregivers, physicians, researchers, and policymakers to optimize awareness, diagnosis, and treatment of this disease. It is time to make COPD care a public health priority. Key words: COPD; COPD exacerbation; economic burden; disparities; primary care physician; tobacco cessation; readmission; discharge bundle; telemedicine; tele-rehabilitation. [Respir Care 2018;63(5):591-600. ( 2018 Daedalus Enterprises] 


\section{Introduction}

COPD is currently the fourth leading cause of death in the United States. ${ }^{1}$ Further, COPD is the cause of significant patient morbidity, affecting the daily lives of millions. ${ }^{1-3}$ Patients struggle with not only the disease itself but also the added burden of obtaining care. There are significant barriers to delivering optimal care for the COPD patient population in the United States, which this review will highlight. Special emphasis will be placed on the high rate of underdiagnosis of COPD in the United States as well as the challenges that patients face in accessing specialty care and needed medications, which are further compounded by socioeconomic disparities. ${ }^{2-8}$ COPD is also associated with periodic exacerbations that result in a significant number of emergency department and in-patient visits. Several new interventions, including discharge bundles, telemedicine, and tele-rehabilitation, have been proposed to reduce readmission rates ${ }^{9-12}$ and will be further examined in this review. Finally, we also outline here the proposed goals of the recently released COPD National Action Plan, which encourages the collaboration of all stakeholders, including patients, caregivers, physicians, researchers, and policymakers, to improve understanding of and treatment for COPD. ${ }^{13}$

\section{Epidemiology}

In 2015, COPD accounted for $>3$ million deaths worldwide, or $5 \%$ of all deaths. ${ }^{14}$ Compared with 1990, COPD accounted for $10 \%$ more deaths and had a $44 \%$ greater prevalence in $2015 .{ }^{14}$ The morbidity and mortality attributable to COPD both globally and nationally is probably even greater than reported due to underdiagnosis and undertreatment of COPD. ${ }^{2,3,15,16}$ An estimated 29 million Americans age $20-79$ y (ie, $15 \%$ of this age group) are living with obstructive lung disease, but only 13 million, or $6.5 \%$, of these adults are aware of their diagnosis. ${ }^{2,3}$

\footnotetext{
Dr Criner is affiliated with the Department of Internal Medicine, and Dr Han is affiliated with the Division of Pulmonary and Critical Care Medicine, University of Michigan, Ann Arbor, Michigan.
}

Dr Criner has disclosed no conflicts of interest. Dr. Han has disclosed relationships with Boehringer Ingelheim, GlaxoSmithKline, AstraZeneca, Sunovion, and Novartis.

Dr Han presented a version of this paper as the 5th annual Thomas L Petty Memorial Lecture at the 63rd AARC Congress, held October 4-7, 2017, in Indianapolis, Indiana.

Correspondence: MeiLan K Han MD MS, University of Michigan, 1500 East Medical Center Drive, TC 3916, Ann Arbor, MI 48109. E-mail: mrking@umich.edu.

DOI: $10.4187 /$ respcare. 06276
Further, those who are aware of their diagnosis do not know the specifics of their disease and its severity. In a national telephone survey administered to $>1,000$ patients with COPD, 79\% knew their blood pressure but only $10 \%$ knew their $\mathrm{FEV}_{1} \cdot{ }^{15} \mathrm{COPD}$ is also characterized by exacerbations that are a significant driver of morbidity, mortality, and cost. In a cohort of $>50,000$ adult Medicare Advantage patients, Dhamane et $\mathrm{al}^{9}$ found that roughly $44 \%$ of subjects had at least one COPD exacerbation over the prior 24-month period. COPD exacerbations accounted for 1.8 million emergency department visits in 2012 with an estimated $20 \%$ subsequently admitted to the hospital. ${ }^{10-12}$

\section{Economic Burden}

\section{Impact on the United States Economy}

COPD is a costly disease, and as its prevalence rises, associated costs will increase. In 2010, the total burden of COPD-attributable costs in the United States was an estimated $\$ 36$ billion, accounting for both direct medical costs as well as absenteeism costs. ${ }^{17}$ By the year 2020, it is projected that national medical costs for COPD will total $\$ 49$ billion. ${ }^{17}$ Exacerbations of COPD account for up to $75 \%$ of the total direct disease cost. ${ }^{9,11}$ Costs associated with in-patient hospitalization for patients with either COPD or bronchiectasis totaled \$18 billion in 2012 (see Fig. 1). ${ }^{10}$

\section{Impact on Patients and Their Caregivers}

COPD results in an estimated 16.4 million days of absenteeism, resulting in $\$ 3.9$ billion in indirect costs in $2010 .{ }^{17}$ Further, the daily symptom burden of COPD leads many to leave the workforce and become dependent on disability benefits. ${ }^{18,19}$ A 2015 Morbidity and Mortality Weekly Report by the Centers for Disease Control and Prevention found that $20.4 \%$ of those with COPD reported inability to work compared with $4.8 \%$ without the disease. ${ }^{18}$ Thornton Snider et al ${ }^{19}$ reported that Americans with COPD who were $\geq 50$ y old were less likely to be employed than those without COPD or those with cancer, heart disease, diabetes, or hypertension. They were also more likely to collect Social Security Disability Insurance and Supplemental Security Income than those with the aforementioned chronic conditions as well as those who had suffered a stroke. ${ }^{19}$ As COPD progresses, patients become more debilitated and dependent on others for daily living and for management of their chronic condition. These informal caregivers, ranging from unpaid family members to friends, also incur indirect costs, with $7 \%$ of caregivers suffering an average of 1.7 lost days of work per year.

Inhalers remain the foundation of optimal medical management of patients with $\mathrm{COPD}^{20}$; However, cost of 


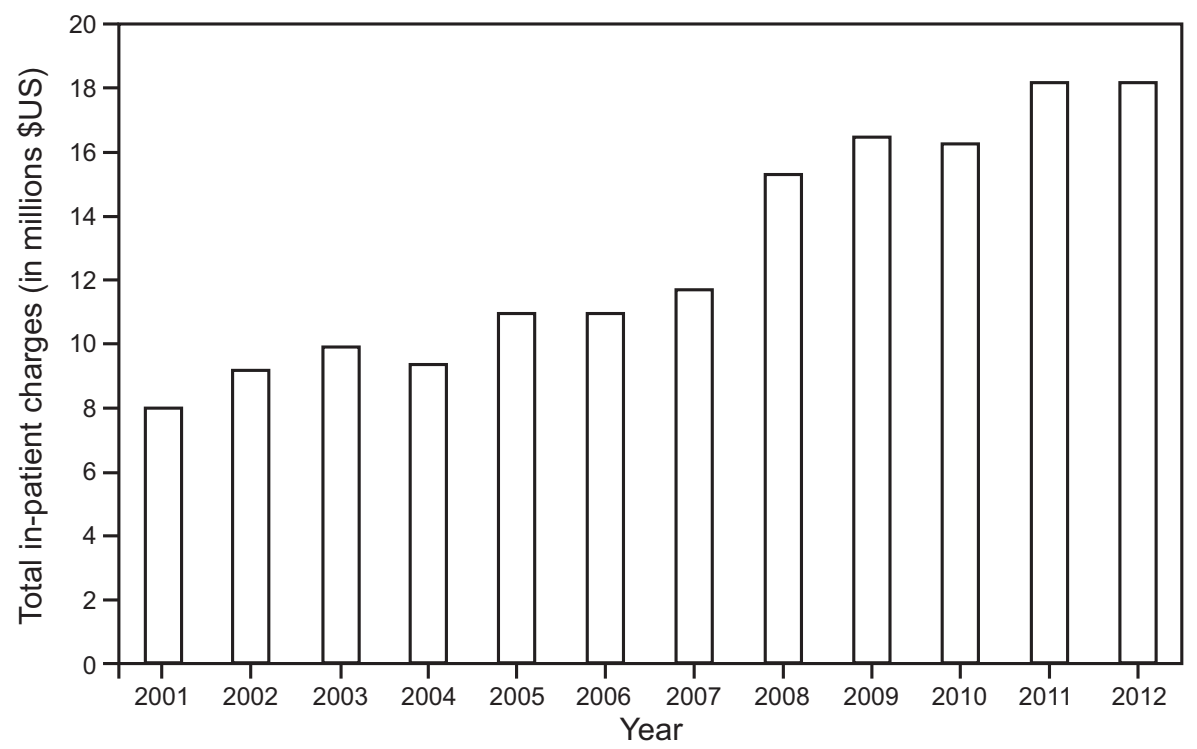

Fig. 1. Aggregate charges for in-patient stays for COPD or bronchiectasis among patients age $\geq 18 \mathrm{y}$, according to the Nationwide Inpatient Sample. Data from Reference 10.

these agents remains a significant burden to many patients. ${ }^{21,22}$ Castaldi et al ${ }^{21}$ found that $31 \%$ of Medicare beneficiaries who were $\geq 65$ y old reported non-adherence to inhaler therapy secondary to cost. A nationwide analysis of Medicare Part D estimated that for just one inhaler, annual out-of-pocket costs exceeded $\$ 900$; for patients with more severe COPD who required 2 or 3 inhalers, the average annual out-of-pocket costs totaled $\$ 1,600$ to $\$ 2,800 .^{22}$

\section{Disparities}

\section{Age}

The prevalence of COPD increases with age. As life expectancy increases and treatment advances, COPD prevalence is expected to grow. ${ }^{23-26}$ Further burdening the aging COPD population is their increased risk for multimorbidity; patients with COPD average 4-6 comorbidities, whereas age-matched controls without COPD average $2-3 .{ }^{26}$ Common comorbid conditions in the COPD population include hypertension, hyperlipidemia, depression, cataracts, osteoporosis, and cancer. ${ }^{15,27,28}$ Mannino et al ${ }^{29}$ found that as $\mathrm{FEV}_{1}$ worsened in subjects with COPD who also had cardiovascular disease, hypertension, and/or diabetes, these subjects had higher significant hospitalization and nonsignificant mortality rates, compared with those without these comorbid conditions.

\section{Gender}

For the past few decades, prevalence of COPD in women has exceeded that in men, despite overall less lifetime cigarette consumption (see Fig. 2). Since 2000, mortality in women has surpassed that in men. ${ }^{16,24,30}$ A $2016 \mathrm{Na}$ tional Center for Health Statistics report found that ageadjusted death rates from COPD have decreased for white and African-American men (2000-2014) but increased for African-American women and remained stagnant for white women during that same time period. ${ }^{31}$ Women may also experience greater lung function decline than men after controlling for the amount of tobacco exposure. ${ }^{32-34}$ Proposed factors include female-specific genetic predisposition to deleterious effects of inhaled tobacco, greater reported dyspnea burden, and a deleterious effect on health-related quality of life and increased airway hyperreactivity in women. ${ }^{34-36}$ Moreover, decreases in estrogen during menopause are thought to promote alveolar loss, possibly increasing women's susceptibility to COPD development. ${ }^{37}$

\section{Socioeconomic}

Within COPD, there is an inverse relationship between prevalence and income level. ${ }^{16,30} \mathrm{COPD}$ prevalence is $1.5-3$ times higher in those with low socioeconomic status compared with those in higher socioeconomic groups. ${ }^{38}$ Lowsocioeconomic status patients account for an estimated two thirds of the COPD population despite comprising $<20 \%$ of the general population. ${ }^{38}$ In general, those who are economically disadvantaged tend to have higher smoking rates, more occupational exposure to inhalant toxins, and greater exposure to air pollution, leading to increased risk for COPD development. ${ }^{38}$ Unfortunately, lower socioeconomic status has also been linked to poorer outcomes, including more severe disease, worse lung func- 


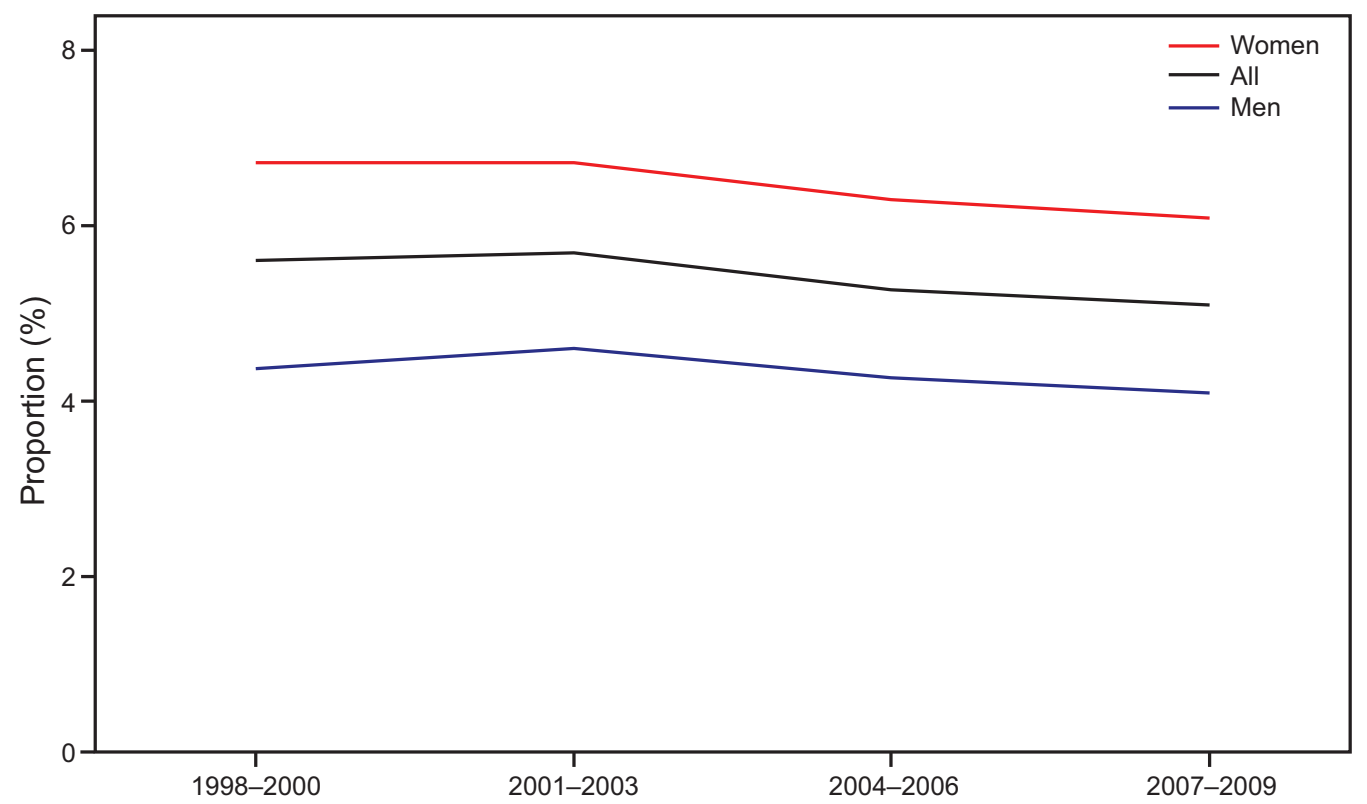

Fig. 2. Prevalence of COPD among adults age $\geq 18 \mathrm{y}$ in the United States from 1998 to 2009. Data from Reference 25.

tion, more physical function limitations, greater risk for COPD exacerbations, and less health-care access. ${ }^{38-40}$ COPD patients with lower income who were also unemployed and/or without a high school degree have higher rates of emergency department visits and hospitalization rates for COPD exacerbation. ${ }^{41}$

\section{Race}

Whereas whites have the highest COPD prevalence and mortality, mortality rates for African-Americans are increasing more rapidly. ${ }^{16,30}$ Further, African-Americans experience more COPD exacerbations requiring hospitalizations than whites as well as worse quality of life associated with COPD exacerbation. ${ }^{42}$ Increased susceptibility to the detrimental effects of tobacco smoke has been suggested as a cause for observed differences. ${ }^{32,33}$ If so, possible contributing factors include lower lung volumes in African-Americans and different inflammatory responses to tobacco smoke. ${ }^{32,33}$

\section{Out-Patient Management}

\section{Role of the Primary Care Physician}

Primary care physicians play a prominent role in COPD diagnosis and management. ${ }^{43}$ According to Perez et al, ${ }^{4} 80 \%$ of COPD care and management is performed by primary care health professionals. Croft et $\mathrm{al}^{5}$ found that 3.7 million adults in the United States do not have access to a pulmonologist within a 1-h driving distance, resulting in primary care physicians, and more recently nurse practitioners and physician assistants, being primarily responsible for diagnosis and subsequent management of the majority of patients with COPD (Fig. 3). ${ }^{6}$ However, patients exclusively managed by primary care physicians are less likely to receive treatment adherent to Global Initiative for Chronic Obstructive Pulmonary Disease (GOLD) guidelines compared with patients managed solely by a pulmonologist or co-managed by their primary care physician and pulmonologist.7,8

In 1998, the National Heart, Lung, and Blood Institute (National Institutes of Health) and the World Health Organization created the GOLD guidelines to not only increase COPD awareness but to somewhat standardize diagnosis and treatment for this chronic disease. ${ }^{20}$ However, despite this better standardization of diagnosis and management, there are significant barriers that health-care professionals in the primary care setting face, including lack of patient-reported dyspnea, time constraints due to management of multiple comorbid conditions, lack of accessibility to spirometry for accepted standard diagnosis, unfamiliarity with pulmonary function test interpretation, and unawareness of the GOLD guidelines. ${ }^{4,6}$ These barriers are thought to contribute to underdiagnosis and undertreatment of COPD. ${ }^{6}$

\section{Preventive Health: Tobacco Cessation}

Primary care providers play a pivotal role in COPD prevention, especially with tobacco cessation assistance, as tobacco abuse is the leading environmental risk factor for COPD and accounts for $80 \%$ of COPD deaths. ${ }^{2,20}$ From 2005 to 2015, the Centers for Disease Control found a $27.7 \%$ decline in current cigarette smoking in United States adults, regardless of gender, socioeconomic status, and 


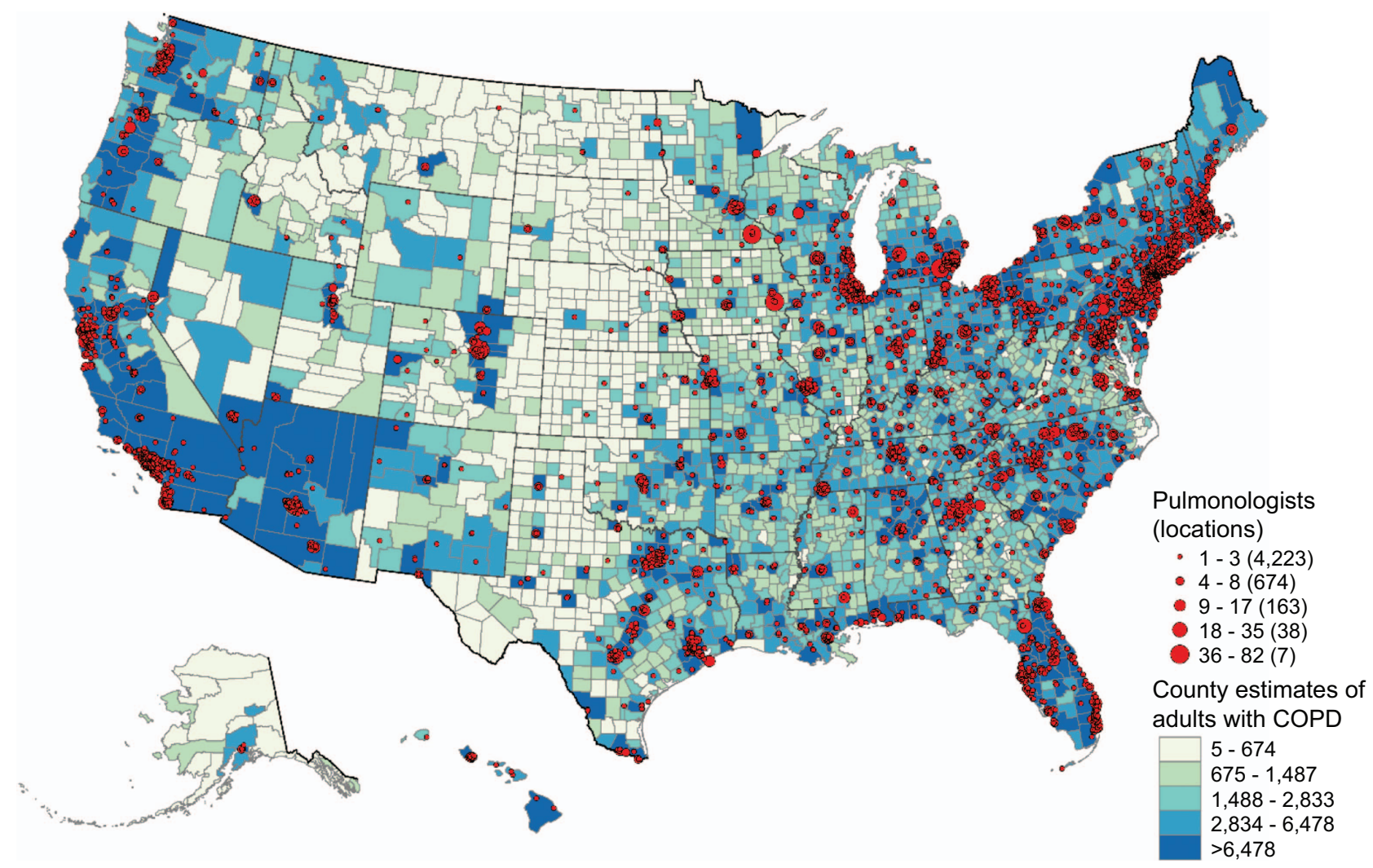

Fig. 3. Locations of 12,392 pulmonologists and quintiles of county estimates of the 15.7 million adults $\geq 18$ y old with diagnosed COPD. From Reference 5, with permission.

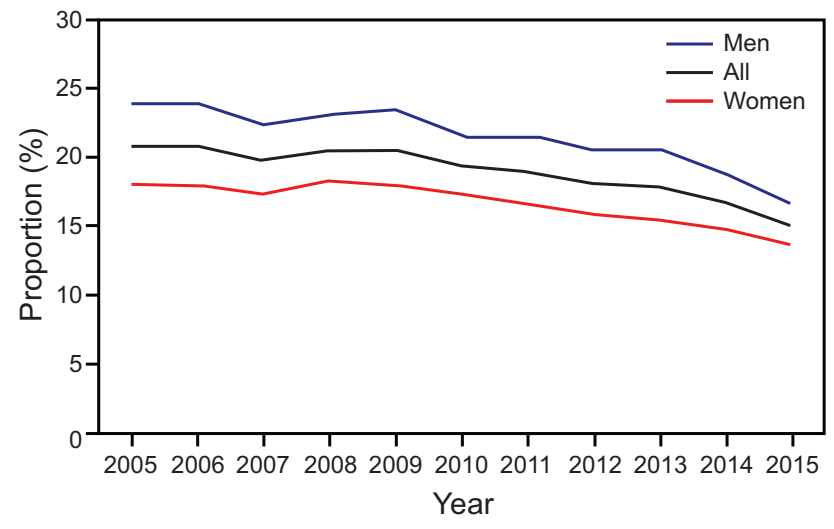

Fig. 4. United States adults who were current cigarette smokers according to the National Health Interview Survey. Data from Reference 45 .

region $(P<.05) .{ }^{44}$ Despite this positive improvement, 36.5 million, or $15.1 \%$, of the United States adult population was still smoking in 2015 (see Fig. 4). ${ }^{44}$

The United States Preventive Services Task Force recommends that all clinicians ask patients about tobacco abuse, advise them to abstain from tobacco, and provide them with behavioral and FDA-approved pharmacologic interventions for patients who do use tobacco. ${ }^{45} \mathrm{~A}$ com- monly used model is the 5 As (ask about tobacco use, advise users to quit, assess willingness to quit, assist in quitting, and arrange follow-up). ${ }^{45}$ Based on the 20052009, National Ambulatory Medical Care Survey and the National Health Interview Survey, $66.6 \%$ of patients underwent tobacco use screening at their primary care visits; however, of those identified as current tobacco users, only $26.9 \%$ actually experienced tobacco counseling, and $8.3 \%$ ended up being prescribed tobacco cessation medication. ${ }^{46}$ Time constraints, lack of significant reimbursement for treatment, lack of institutional support for screening and treatment, and lack of knowledge by primary care physicians were thought to be significant barriers. ${ }^{46}$

\section{Pulmonary Rehabilitation}

Pulmonary rehabilitation is a highly recommended but underutilized intervention for COPD patients with persistent symptoms despite optimal medical therapy. ${ }^{20,47}$ At least 4 weeks of exercise training with patient education improves dyspnea, fatigue, and functional exercise capacity as well as reducing readmission rates and overall healthcare utilization. ${ }^{48-50}$ However, the survey by Barr et $\mathrm{al}^{47}$ found that only $19 \%$ of primary care physicians and 54\% of pulmonologists regularly refer their patients to pulmo- 
nary rehabilitation despite the majority of these physicians understanding that their moderate-to-severe COPD patients would benefit. Specific barriers include cost, poor insurance coverage, lack of perceived benefit by patients, and unavailability, with $23 \%$ of primary care physicians and $8 \%$ of pulmonologists reporting no available programs to them. ${ }^{47,51}$ For patients in rural areas, transportation to such programs also represents a real problem.

In an effort to combat these barriers, home tele-rehabilitation initiatives have been developed with promising results. ${ }^{49,52}$ Holland et al ${ }^{52}$ created a home-based pulmonary rehabilitation program, during which subjects were visited by a physical therapist at their home at week 1 and taught exercise techniques using readily available household equipment. Subjects were then followed up by telephone weekly for a total of 8 weeks. This tele-rehabilitation program was not inferior to the standard out-patient pulmonary rehabilitation program with regard to short-term quality of life and exercise capacity improvements at 8-week follow-up.

In a randomized trial in Canada, Maltais et $\mathrm{al}^{49}$ found that a self-monitored, home-based rehabilitation with weekly telephone calls with an exercise trainer was not inferior to the traditional out-patient rehabilitation program at $1 \mathrm{y}$. Researchers in the United Kingdom randomized subjects upon hospital discharge for a COPD exacerbation to a home-based exercise and educational program with biweekly telephone follow-up compared with usual care; they found that participants in the intervention arm had a nonsignificant decrease in 30-d readmission rate compared with the usual care arm. ${ }^{53}$

\section{Curbing Readmission Rates}

Since the turn of the 21 st century, total emergency department visit and hospitalization rates have increased for COPD, with exacerbations accounting for $62.5 \%$ of admission reasons. ${ }^{10,54}$ Both emergency department visits and readmissions for COPD exacerbations account for the majority of COPD-related costs. ${ }^{9}{ }^{11}$ Although the GOLD committee has issued recommendations for management of COPD exacerbations, adherence varies. ${ }^{20,55,56}$ There have been recent efforts by health-care systems to better adhere to expert-level recommendations and to better coordinate management, as the 30-d readmission rate currently exceeds 20\%.57,58 Furthermore, in 2014, the Center for Medicare Services added exacerbations of COPD to the Hospital Readmission Reduction Program, which is a government effort to reduce Medicare payments to Inpatient Prospective Payment System hospitals with excessive 30-day all-cause readmission rates. ${ }^{57}$

Recurrent exacerbations account for $27.6 \%$ of all readmissions based on a 2006-2010 review of In-patient Prospective Payment System hospitals receiving Medicare fee- for-service beneficiaries. ${ }^{57}$ Patients discharged home without home care after their index COPD exacerbation admission are also more likely to be readmitted for COPD than those discharged to post-acute care, which includes short-term rehabilitation facilities as well as home care services $(31.1 \%$ vs $18.8 \%, P<.001) .{ }^{57}$ Other readmission risk factors include longer lengths of stay during the index admission and a greater number of comorbidities and specific comorbidities, including heart failure, obstructive sleep apnea, vertebral fractures, anemia, anxiety, depression, and electrolyte and acid/base disorders. ${ }^{57,59}$ To curb COPD's high readmission rates, various solutions have been proposed, including in-patient electronic order sets, discharge bundles, hospital at-home programs, telemedicine, and tele-rehabilitation. However, at this time, no single intervention has emerged as a generalizable model to consistently reduce $30-\mathrm{d}$ readmission rates. This is probably related to the complex set of comorbidities and social factors that contribute to readmissions beyond COPD itself.

\section{Electronic Order Sets}

Implementation of an in-patient electronic order set for exacerbation management has been shown to increase prescriber adherence to recommended medications and an overall stay reduction but had no effect on 30-d readmission rates. ${ }^{60}$ When Sonstein et al ${ }^{61}$ implemented an electronic order set, they also found greater provider adherence to GOLD medication recommendations but no effect on stay or readmission rate.

\section{Discharge Bundles}

Other efforts to combat high readmission rates have focused on implementation of discharge bundles, although with variable results. A United Kingdom research group implemented a COPD discharge care bundle, in which all patients admitted to the respiratory ward for exacerbations were provided with tobacco cessation and COPD education information, assessed for pulmonary rehabilitation appropriateness and proper inhaler technique, and scheduled with a pulmonary specialist within 1 month of discharge. Their efforts led to a nonsignificant decline in 30-d readmission rates. ${ }^{62}$

A group of Ohio researchers implemented its own variation of a discharge care bundle that focused heavily on inhaler technique, clear discharge instructions with COPD education, and timely follow-up. ${ }^{63}$ Despite not including tobacco cessation, vaccinations, and pulmonary rehabilitation referrals, this group found a significant decline in 30 - $\mathrm{d}$ readmission rate $(22.7 \%$ before COPD bundle, $14.7 \%$ after COPD bundle). ${ }^{63}$ However, Jennings et al ${ }^{64}$ found no difference in 30- and 90-d emergency room visit and readmission rates after implementation of a discharge bun- 
dle $24 \mathrm{~h}$ before discharge, which included smoking cessation; COPD education with a focus on inhaler technique; screening for and potential management of gastroesophageal reflux disease, anxiety, and depression; and telephone follow-up at $48 \mathrm{~h}$.

Conversely, Alshabanat et al ${ }^{65}$ implemented a comprehensive care management program, in which respiratory therapists, nurses, and nurse practitioners followed patients with COPD for $90 \mathrm{~d}$ post-discharge with home and/or telephone support, focusing on clinical assessment, medication and inhaler technique review, COPD education, and multidisciplinary support. This program was piloted at 5 Vancouver hospitals and resulted in a significant reduction in COPD and all-cause readmissions and in stay for COPD-related readmissions. ${ }^{65}$ Lawlor et al ${ }^{66}$ coupled early discharge with a discharge bundle program in which subjects with COPD exacerbation were discharged to home within $4 \mathrm{~d}$ of admission or earlier and received education regarding COPD, inhaler technique, and home physical therapy exercises and were provided with smoking cessation counseling and rapid access to a pulmonary clinic if they felt they were experiencing a recurrent exacerbation; this program led to a significant reduction in emergency department visits and 6- and 12-month readmission rates when comparing the same subjects preand post-implementation. ${ }^{66}$

\section{Hospital at Home}

For a select group of patients experiencing an exacerbation, some evidence suggests that discharge directly to home from the emergency department with appropriate medications and regular at-home respiratory nurse follow-up is associated with a significantly reduced readmission rate and nonsignificant reduction in mortality rate, compared with similar patients who received in-patient care. ${ }^{67}$ Although this concept has shown some promising results, a Cochrane review of 8 studies that explored this intervention only found about $25 \%$ of their study population appropriate for this type of care, as the majority of patients met various exclusion criteria, including impaired consciousness, chest radiograph or electrocardiogram abnormalities, $\mathrm{pH}<7.35$, poor lung function, and/or severe comorbidities. ${ }^{67}$

\section{Telemedicine}

Telemedicine has garnered significant attention in the past decade. By monitoring patients' symptoms and vital signs via various technological means, including web-based visits, telephone visits, and/or electronic diaries monitored by health-care personnel, it is proposed that COPD exacerbations can be detected earlier with the end goal of reducing emergency department visits and hospitalization rates. ${ }^{68}$ However, telemedicine remains controversial due to conflicting results in the setting of non-standardization of techniques. ${ }^{69}$

Trappenburg et $\mathrm{al}^{70}$ found that an electronic diary for daily symptom reporting paired with medication compliance and COPD education questions led to a significant reduction in the rate of hospital admissions and COPD exacerbations. A randomized, controlled trial by Bourbeau et $\mathrm{al}^{71}$ found that subjects with COPD who underwent a weekly COPD education program for 2 months with monthly telephone follow-up experienced decreased hospital admissions for COPD exacerbations and a reduction in all-cause admissions at 12 months, compared with subjects receiving usual care. An Italian randomized controlled trial found that subjects with COPD who were dependent on either long-term oxygen therapy or home mechanical ventilation and who were provided with continuous pulse oximeter monitoring and 24-h access to a nurse-centered tele-assistance hotline had fewer exacerbations, emergency department visits, and admissions. ${ }^{72}$

Although Cordova et $\mathrm{al}^{73}$ found daily peak flow and dyspnea to improve in subjects with COPD who entered daily COPD-related symptoms via a smartphone application, there was no reduction in readmission rates or stay. Pinnock et $\mathrm{al}^{74}$ also found no significant decrease in COPD readmission rate or stay for subjects with COPD who answered a daily symptom questionnaire on a touchscreen and provided oxygen saturation data. Ringbaek et al ${ }^{68}$ found that video consultation with patients with COPD and respiratory nurses led to fewer out-patient visits but not COPD-related or all-cause hospitalization rates.

Casas et al ${ }^{75}$ combined discharge bundles with telemedicine. Subjects hospitalized for COPD exacerbation were randomized to usual care versus an integrated care intervention that included assessment of disease severity, comorbidities, social needs, and self-management before discharge. Participants were also provided an individualized care plan that was shared between a specialized nurse case manager and subjects' primary care physicians and a web-based call center managed by the specialized nurse accessible to both subjects and primary care physicians over a 12-month follow-up period. ${ }^{75}$ After 12 months, the integrated care arm had a significantly decreased readmission rate for COPD exacerbations $(1.5 \pm 2.6$ in the integrated arm vs $2.1 \pm 3.1, P=.033) .^{75}$ This same integrated care model was then applied to COPD out-patients. ${ }^{76}$ Over a 6-y follow-up period, the integrated care arm had a significant reduction in emergency department visits but no difference in admission rates. Importantly, however, $80 \%$ of the admissions for the integrated care group were scheduled via the subjects' primary care physician and inpatient team, whereas $100 \%$ of the usual care group admissions were unscheduled and thus via the emergency department. ${ }^{76}$ 


\section{Future Directions: COPD National Action Plan}

The Department of Health and Human Services, National Institutes of Health, and Centers for Disease Control and Prevention released the COPD National Action Plan in 2017 to foster greater awareness to COPD, as it remains a largely preventable disease that continues to burden millions of Americans, many of whom are not diagnosed, with both disability and death and remains an economic strain on the health-care system. ${ }^{13}$ The plan was a collaborative effort of not only government agencies but also a range of COPD stakeholders, including patients and their caregivers, health-care providers, and nonprofit organizations. Five broad goals were announced, with each goal pertaining to a key stakeholder in the disease.

The goals are as follows: (1) raise public awareness of COPD, its symptoms, and its causes by focusing on educating patients and their caregivers; (2) improve training for health-care professionals in diagnosis, prevention, and treatment of COPD, and promote collaboration among all health-care professionals to create a national standardized, patient-centered treatment and prevention algorithm; (3) encourage data sharing to improve analysis of COPD-related public health data and prioritize dissemination of the results; (4) focus research efforts on identifying COPD earlier and preventing its progression, on understanding different COPD clinical phenotypes, and on developing personalized medicine as well as continuing research efforts to optimize COPD treatment; and (5) create an organization with both federal and non-federal partners that focuses on implementing the COPD National Action Plan's goals, generates funding, and implements public health prevention strategies. ${ }^{13}$

The COPD National Action Plan is a call to all those affected by COPD, whether they are patients, family members, researchers, physicians, or public policy officials, to focus on this largely preventable, national disease growing in prevalence and incidence. It acknowledges the importance of research and data collaboration; however, it also places strong emphasis on the role of public health campaigns and empowerment of patients and their families. However, it is important to remember that by itself, it is only a plan. Implementation will require the engagement of all stakeholders to fulfill its goals.

\section{Summary}

Despite being a largely preventable disease, the global and national burden of COPD remains high. The collaboration highlighted by the COPD National Action Plan is a great step forward in acknowledging that COPD can only be effectively prevented and treated if all stakeholders are invested. However, continued collaboration at the ground level is needed, as many patients continue to be burdened by daily symptoms and barriers to diagnosis and optimal management. Future endeavors will need to focus on the coordination of primary care physicians, pulmonologists, nurses, and respiratory therapists in both the out-patient and in-patient settings to ensure patients receive optimal treatment and education and frequent monitoring for early signs of an exacerbation.

Greater emphasis must be placed on educating primary care health-care professionals on the signs and symptoms of COPD to aid earlier diagnosis and on GOLD standard treatment recommendations. Public health education programs need to be widely publicized so that undiagnosed patients receive treatment earlier. For both the in-patient and out-patient settings, there must be stronger efforts on tobacco cessation screening and treatment strategies to curb morbidity and mortality rates. The various new strategies to combat high COPD exacerbation readmission rates, such as discharge bundles, telemedicine, and tele-rehabilitation, have shown some promise. However, there must be continued application of these interventions to larger patient populations to determine whether their effects are generalizable, sustainable, and economically feasible.

\section{REFERENCES}

1. Kochanek KD, Murphy SL, Xu J, Arias E. Mortality in the United States, 2016. Atlanta, Georgia: Centers for Disease Control and Prevention; 2017.

2. Ford ES, Croft JB, Mannino DM, Wheaton AG, Zhang X, Giles WH. COPD Surveillance-United States, 1999-2011. Chest 2013;144(1): 284-305.

3. Ford ES, Mannino DM, Wheaton AG, Giles WH, Presley-Cantrell L, Croft JB. Trends in the prevalence of obstructive and restrictive lung function among adults in the United States: findings from the $\mathrm{Na}$ tional Health and Nutrition Examination surveys from 1988-1994 to 2007-2010. Chest 2013;143(5):1395-1406.

4. Perez X, Wisnivesky JP, Lurslurchachai L, Kleinman LC, Kronish IM. Barriers to adherence to COPD guidelines among primary care providers. Respir Med 2012;106(3):374-381.

5. Croft JB, Lu H, Zhang X, Holt JB. Geographic accessibility of pulmonologists for adults with COPD: United States, 2013. Chest 2016;150(3):544-553.

6. Yawn BP, Wollan PC, Textor KB, Yawn RA. Primary care physicians', nurse practitioners' and physician assistants' knowledge, attitudes and beliefs regarding COPD: 2007 to 2014. Chronic Obstr. Pulm. Dis. 2016;3(3):628-635.

7. Sharif R, Cuevas CR, Wang Y, Arora M, Sharma G. Guideline adherence in management of stable chronic obstructive pulmonary disease. Respir Med 107(7):1046-1052.

8. Glaab T, Vogelmeier C, Hellmann A, Buhl R. Guideline-based survey of outpatient COPD management by pulmonary specialists in Germany. Int J COPD 2012;7:101-108.

9. Dhamane AD MC, Zhou Y, et al. COPD exacerbation frequency and its association with health care resource utilization and costs. Int J COPD 2015;10:2609-2618.

10. Ford ES. Hospital discharges, readmissions, and ED visits for COPD or bronchiectasis among US adults: findings from the nationwide inpatient sample 2001-2012 and Nationwide Emergency Department Sample 2006-2011. Chest 2015;147(4):989-998. 
11. Perera PN, Armstrong EP, Sherrill DL, Skrepnek GH. Acute exacerbations of COPD in the United States: inpatient burden and predictors of costs and mortality. COPD 2012;9(2):131-141.

12. Jinjuvadia C, Jinjuvadia R, Mandapakala C, Durairajan N, Liangpunsakul S, Soubani AO. Trends in outcomes, financial burden, and mortality for acute exacerbation of chronic obstructive pulmonary disease (COPD) in the United States from 2002 to 2010. COPD 2017;14(1):72-79.

13. Department of Health and Human Services, Centers for Disease Control and Prevention, and NHLBI, National Institutes of Health. COPD National Action Plan. 2017. NIH Publication No. 17-HL8031. https://www.nhlbi.nih.gov/sites/default/files/media/docs/ COPD\%20National\%20Action\%20Plan\%20508_0.pdf. Accessed April 4, 2018.

14. GBD 2015 Chronic Respiratory Disease Collaborators. Global, regional, and national deaths, prevalence, disability-adjusted life years, and years lived with disability for chronic obstructive pulmonary disease and asthma, 1990-2015: a systematic analysis for the Global Burden of Disease Study 2015. Lancet Respir Med 2017;5(9):691706.

15. Barr RG, Celli BR, Mannino DM, Petty T, Rennard SI, Sciurba FC, et al. Comorbidities, patient knowledge, and disease management in a national sample of patients with COPD. Am J Med 2009;122(4): 348-355.

16. Mannino DM, Homa DM, Akinbami LJ, Ford ES, Redd SC. Chronic obstructive pulmonary disease-United States, 1971-2000. MMWR Surveill Summ 2002;51(6):1-16.

17. Ford ES, Murphy LB, Khavjou O, Giles WH, Holt JB, Croft JB. Total and state-specific medical and absenteeism costs of COPD among adults aged 18 years in the United States for 2010 and projections through 2020. Chest 2015;147(1):31-45.

18. Wheaton AG, Cunningham TJ, Ford ES, Croft JB, Centers for Disease Control and Prevention (CDC). Employment and activity limitations among adults with chronic obstructive pulmonary diseaseUnited States, 2013. MMWR Morb Mortal Wkly Rep 2015;64(11): 289-295.

19. Thornton Snider J, Romley JA, Wong KS, Zhang J, Eber M, Goldman DP. The disability burden of COPD. COPD 2012;9(5):513-521.

20. Global Initiative for Chronic Obstructive Lung Disease (GOLD). Global strategy for the prevention, diagnosis, and management of COPD, 2018. http://goldcopd.org. Accessed March 29, 2018.

21. Castaldi PJ, Rogers WH, Safran DG, Wilson IB. Inhaler costs and medication nonadherence among seniors with chronic pulmonary disease. Chest 2010;138(3):614-620.

22. Tseng CW, Yazdany J, Dudley RA, DeJong C, Kazi DS, Chen R, Lin GA. Medicare Part D plans' coverage and cost-sharing for acute rescue and preventive inhalers for chronic obstructive pulmonary disease. JAMA Int Med 2017;177(4):585-588.

23. Rycroft CE, Heyes A, Lanza L, Becker K. Epidemiology of chronic obstructive pulmonary disease: a literature review. Int J Chron Obstruct Pulmon Dis 2012;7(Can't get issue from record):457-494.

24. Akinbami LJ, Xiang L. Chronic Obstructive Pulmonary Disease Among Adults Aged 18 and Over in the United States, 1998-2009. NCHS Data Brief No. 63. Hyattsville, MD: National Center for Health Statistics; 2011.

25. Peruzza S, Sergi G, Vianello A, Pisent C, Tiozzo F, Manzan A, et al. Chronic obstructive pulmonary disease (COPD) in elderly subjects: impact on functional status and quality of life. Respir Med 2003; 97(6):612-617.

26. Divo MJ, Martinez CH, Mannino DM. Ageing and the epidemiology of multimorbidity. Eur Respir J 2014;44(4):1055-1068.

27. Ansari S, Hosseinzadeh H, Dennis S, Zwar N. Patients' perspectives on the impact of a new COPD diagnosis in the face of multimor- bidity: a qualitative study. NPJ Prim Care Respir Med 2014;24: 14036.

28. de Torres JP, Casanova C, Marín JM, Pinto-Plata V, Divo M, Zulueta JJ, et al. Prognostic evaluation of COPD patients: GOLD 2011 versus BODE and the COPD comorbidity index COTE. Thorax 2014; 69(9):799-804.

29. Mannino DM, Thorn D, Swensen A, Holguin F. Prevalence and outcomes of diabetes, hypertension and cardiovascular disease in COPD. Eur Respir J 2008;32(4):962-969.

30. Centers for Disease Control and Prevention (CDC). Chronic obstructive pulmonary disease among adults-United States, 2011. MMWR Morb Mortal Wkly Rep 2012;61(46):938-943.

31. Ni H XJ. COPD-related mortality by sex and race among adults aged 25 and over: United States, 2000-2014. NCHS Data Brief 2016;256.

32. Chatila WM, Wynkoop WA, Vance G, Criner GJ. Smoking patterns in African Americans and whites with advanced COPD. Chest 2004; 125(1):15-21.

33. Dransfield MT, Davis JJ, Gerald LB, Bailey WC. Racial and gender differences in susceptibility to tobacco smoke among patients with chronic obstructive pulmonary disease. Respir Med 2006;100(6): 1110-1116.

34. Han MK, Postma D, Mannino DM, Giardino ND, Buist S, Curtis JL, Martinez EJ. Gender and chronic obstructive pulmonary disease: why it matters. Am J Respir Crit Care Med 2007;176(12):11791184.

35. United States Department of Health and Human Services. The Health Consequences of Smoking-50 Years of Progress: A Report of the Surgeon General. Atlanta, Georgia: United States Department of Health and Human Services, Centers for Disease Control and Prevention, National Center for Chronic Disease Prevention and Health Promotion, Office on Smoking and Health; 2014:701-770.

36. Kanner RE, Connett JE, Altose MD, Buist AS, Lee WW, Tashkin DP, Wise RA. Gender difference in airway hyperresponsiveness in smokers with mild COPD: the lung health study. Am J Respir Crit Care Med 1994;150(4):956-961.

37. Kamil F, Pinzon I, Foreman MG. Sex and race factors in early-onset COPD. Curr Opin Pulm Med 2013;19(2):140-144.

38. Pleasants RA, Riley IL, Mannino DM. Defining and targeting health disparities in chronic obstructive pulmonary disease. Int J Chron Obstruct Pulmon Dis 2016;11:2475-2496.

39. Eisner MD, Blanc PD, Omachi TA, Yelin EH, Sidney S, Katz PP, et al. Socioeconomic status, race, and COPD health outcomes. J Epidemiol Community Health 2011;65(1):26-34.

40. Gershon AS, Dolmage TE, Stephenson A, Jackson B. Chronic obstructive pulmonary disease and socioeconomic status: a systematic review. COPD 2012;9(3):216-226.

41. Kumbhare SD, Beiko T, Wilcox SR, Strange C. Characteristics of COPD patients using United States emergency care or hospitalization. COPD 2016;3(2):539-548.

42. Han MK, Curran-Everett D, Dransfield MT, Criner GJ, Zhang L, Murphy JR, et al. Racial differences in quality of life in patients with COPD. Chest 2011;140(5):1169-1176.

43. Bernd L, Joan BS, Michael S, Bernhard K, Lowie EV, Louisa G, et al. Determinants of underdiagnosis of COPD in national and international surveys. Chest 2015;148(4):971-985.

44. Jamal A, King BA, Neff LJ, Whitmill J, Babb SD, Graffunder CM. Current cigarette smoking among adults-United States, 2005-2015. MMWR Morb Mortal Wkly Rep 2016;65(44):1205-1211.

45. Siu AL, U.S. Preventive Services Task Force. Behavioral and pharmacotherapy interventions for tobacco smoking cessation in adults, including pregnant women: U.S. preventive services task force recommendation statement. Ann Intern Med 2015;163(8):622-634.

46. Jamal A, Dube SR, Malarcher AM, Shaw L, Engstrom MC, Centers for Disease Control and Prevention (CDC). Tobacco use screening and 
counseling during physician office visits among adults—National Ambulatory Medical Care Survey and National Health Interview Survey, United States, 2005-2009. MMWR Suppl 2012;61(2):38-45.

47. Barr RG, Celli BR, Martinez FJ, Ries AL, Rennard SI, Reilly JJ, et al. Physician and patient perceptions in COPD: the COPD Resource Network needs assessment survey. Am J Med 2005;118(12): 1415.

48. McCarthy B CD, Devane D, Murphy K, Murphy E, Lacasse Y. Pulmonary rehabilitation for chronic obstructive pulmonary disease. Cochrane Database Syst Rev 2015;(2):CD003793.

49. Maltais F, Bourbeau J, Shapiro S, Lacasse Y, Perrault H, Baltzan M, et al. Effects of home-based pulmonary rehabilitation in patients with chronic obstructive pulmonary disease: a randomized trial. Ann Intern Med 2008;149(12):869-878.

50. Puhan MA, Gimeno-Santos E, Scharplatz M, Troosters T, Walters $\mathrm{EH}$, Steurer J. Pulmonary rehabilitation following exacerbations of chronic obstructive pulmonary disease (review). Cochrane Database Syst Rev 2011;(10):1-41.

51. Sohanpal R, Steed L, Mars T, Taylor SJC. Understanding patient participation behaviour in studies of COPD support programmes such as pulmonary rehabilitation and self-management: a qualitative synthesis with application of theory. NPJ Prim Care Respir Med 2015;25:15054.

52. Holland AE, Mahal A, Hill CJ, Lee AL, Burge AT, Cox NS, et al. Home-based rehabilitation for COPD using minimal resources: a randomised, controlled equivalence trial. Thorax 2017;72(1):57-65.

53. Johnson-Warrington V, Rees K, Gelder C, Morgan MD, Singh SJ. Can a supported self-management program for COPD upon hospital discharge reduce readmissions? A randomized controlled trial. Int J Chron Obstruct Pulmon Dis 2016;11:1161-1169.

54. Wier LM, Elixhauser A, Pfuntner A, Au DH. Overview of hospitalizations among patients with COPD, 2008. HCUP Statistical Brief \#106. February 2011. Rockville, Maryland: Agency for Healthcare Research and Quality. http://www.hcup-us.ahrq.gov/reports/ statbriefs/sb106.pdf. Accessed March 29, 2018.

55. Roberts CM, Lopez-Campos JL, Pozo-Rodriguez F, Hartl S. European hospital adherence to GOLD recommendations for chronic obstructive pulmonary disease (COPD) exacerbation admissions. Tho$\operatorname{rax} 2013 ; 68(12): 1169-1171$.

56. Tang CY, Taylor NF, McDonald CF, Blackstock FC. Level of adherence to the GOLD strategy document for management of patients admitted to hospital with an acute exacerbation of COPD. Respirology 2014;19(8):1191-1197.

57. Shah T, Churpek MM, Coca Perraillon M, Konetzka RT. Understanding why patients with COPD get readmitted: a large national study to delineate the Medicare population for the readmissions penalty expansion. Chest 2015;147(5):1219-1226.

58. Jencks SF, Williams MV, Coleman EA. Rehospitalizations among patients in the Medicare Fee-for-Service Program. N Engl J Med 2009;360(14):1418-1428.

59. Glaser JB, El-Haddad H. Exploring novel Medicare readmission risk variables in chronic obstructive pulmonary disease patients at high risk of readmission within 30 days of hospital discharge. Ann Am Thorac Soc 2015;12(9):1288-1293.

60. Brown KE, Johnson KJ, DeRonne BM, Parenti CM, Rice KL. Order set to improve the care of patients hospitalized for an exacerbation of chronic obstructive pulmonary disease. Ann Am Thorac Soc 2016; 13(6):811-815.
61. Sonstein L, Clark C, Seidensticker S, Zeng L, Sharma G. Improving adherence for management of acute exacerbation of chronic obstructive pulmonary disease. Am J Med 2014;127(11):1097-1104.

62. Hopkinson NS, Englebretsen C, Cooley N, Kennie K, Lim M, Woodcock $\mathrm{T}$, et al. Designing and implementing a COPD discharge care bundle. Thorax 2012;67(1):90-92.

63. Zafar MA, Panos RJ, Ko J, Otten LC, Gentene A, Guido M, et al. Reliable adherence to a COPD care bundle mitigates system-level failures and reduces COPD readmissions: a system redesign using improvement science. BMJ Qual Saf 2017;26(11):908-918.

64. Jennings JH, Thavarajah K, Mendez MP, Eichenhorn M, Kvale P, Yessayan L. Predischarge bundle for patients with acute exacerbations of COPD to reduce readmissions and ED visits. Chest;147(5): 1227-1234.

65. Alshabanat A, Otterstatter MC, Sin DD, Road J, Rempel C, Burns J, et al. Impact of a COPD comprehensive case management program on hospital length of stay and readmission rates. Int J Chron Obstruct Pulmon Dis 2017;12:961-971.

66. Lawlor M, Kealy S, Agnew M, Korn B, Quinn J, Cassidy C, et al. Early discharge care with ongoing follow-up support may reduce hospital readmissions in COPD. Int J Chron Obstruct Pulmon Dis 2009;4:55-60.

67. Jeppesen E, Brurberg KG, Vist GE, Wedzicha JA, Wright JJ, Greenstone M, et al. Hospital at home for acute exacerbations of chronic obstructive pulmonary disease. Cochrane Database Syst Rev 2012; (5):1-48.

68. Ringbaek T, Green A, Laursen LC, Frausing E, Brøndum E, Ulrik CS. Effect of tele health care on exacerbations and hospital admissions in patients with chronic obstructive pulmonary disease: a randomized clinical trial. Int J Chron Obstruct Pulmon Dis 2015;10: 1801-1808.

69. Goldstein RS, O'Hoski S. Telemedicine in COPD: time to pause. Chest 2014;145(5):945-949.

70. Trappenburg JC, Niesink A, de Weert-van Oene GH, van der Zeijden H, van Snippenburg R, Peters A, Lammers JWJ, Schrijvers AJP. Effects of telemonitoring in patients with chronic obstructive pulmonary disease. Telemed J E Health 2008;14(2):138-146.

71. Bourbeau J, Julien M, Maltais F, Rouleau M, Beaupré A, Bégin R, et al. Reduction of hospital utilization in patients with chronic obstructive pulmonary disease: A disease-specific self-management intervention. Arch Intern Med 2003;163(5):585-591.

72. Vitacca M, Bianchi L, Guerra A, Fracchia C, Spanevello A, Balbi B, Scalvini S. Tele-assistance in chronic respiratory failure patients: a randomised clinical trial. Eur Respir J 2009;33(2):411-418.

73. Cordova FC, Ciccolella D, Grabianowski C, Gaughan J, Brennan K, Goldstein F, et al. A telemedicine-based intervention reduces the frequency and severity of COPD exacerbation symptoms: a randomized, controlled trial. Telemed J E Health 2016;22(2):114-122.

74. Pinnock H, Hanley J, McCloughan L, Todd A, Krishan A, Lewis S, et al. Effectiveness of telemonitoring integrated into existing clinical services on hospital admission for exacerbation of chronic obstructive pulmonary disease: researcher blind, multicentre, randomised controlled trial. BMJ 2013;347:f6070.

75. Casas A, Troosters T, Garcia-Aymerich J, Roca J, Hernández C, Alonso A, et al. Integrated care prevents hospitalisations for exacerbations in COPD patients. Eur Respir J 2006;28(1):123-130.

76. Hernández C, Alonso A, Garcia-Aymerich J, Serra I, Marti D, Rodriguez-Roisin R, et al. Effectiveness of community-based integrated care in frail COPD patients: a randomised controlled trial. NPJ Prim Care Respir Med 2015;25:15022. 